Provided for non-commercial research and education use. Not for reproduction, distribution or commercial use.

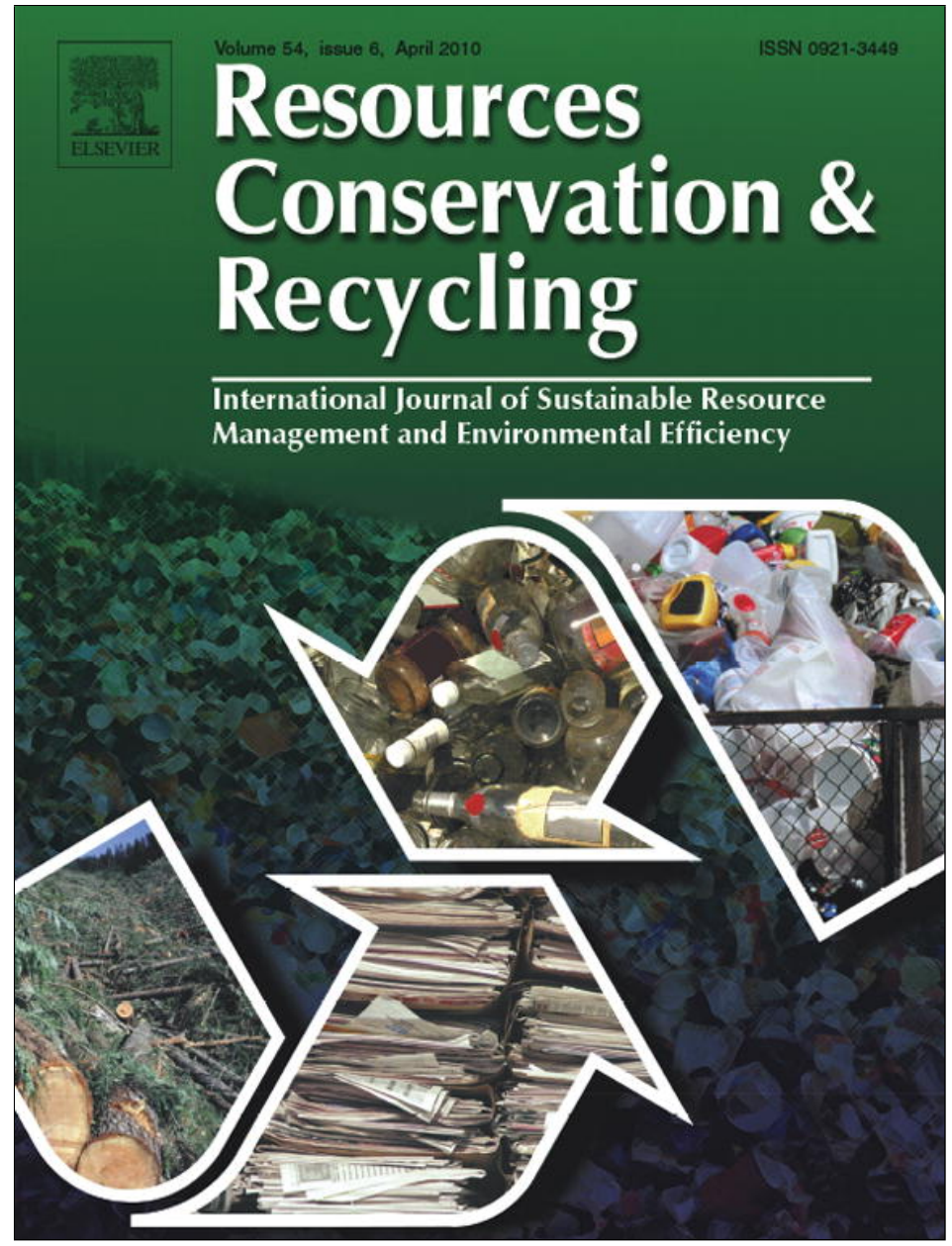

This article appeared in a journal published by Elsevier. The attached copy is furnished to the author for internal non-commercial research and education use, including for instruction at the authors institution and sharing with colleagues.

Other uses, including reproduction and distribution, or selling or licensing copies, or posting to personal, institutional or third party websites are prohibited.

In most cases authors are permitted to post their version of the article (e.g. in Word or Tex form) to their personal website or institutional repository. Authors requiring further information regarding Elsevier's archiving and manuscript policies are encouraged to visit:

http://www.elsevier.com/copyright 


\title{
Sensitivity of the LCA allocation procedure for BFS recycled into pavement structures
}

\author{
Shahinaz Sayagh ${ }^{\mathrm{a}, \mathrm{b}}$, Anne Ventura $^{\mathrm{a}, *}{ }$, Tung Hoang a,c ${ }^{\mathrm{a}}$, Denis François ${ }^{\mathrm{a}}$, Agnès Jullien $^{\mathrm{a}}$ \\ a LCPC, Route de Bouaye, BP 4129, 44341 Bouguenais cedex, France \\ ${ }^{\mathrm{b}}$ ADEME, 20, avenue du Grésillé, BP 90406, 49004 Angers cedex 01, France \\ ${ }^{c}$ Hanoï University of Civil Engineering, No. 5 Giai Phong Road, Hanoï, Viet Nam
}

\section{A R T I C L E I N F O}

\section{Article history:}

Received 17 March 2009

Accepted 30 August 2009

\section{Keywords:}

Life cycle assessment

Road construction

Road maintenance

Procedure for allocating emissions to

several impact categories

Waste recycling

\begin{abstract}
A B S T R A C T
The purpose of this paper is twofold: to investigate the problems involved when performing an environmental assessment of various pavements structures and to establish the method applied to solutions proposed by official French guidelines. This assessment will be performed by employing the life cycle assessment (LCA) methodology specifically adapted to road pavements through a parametric environmental evaluation tool developed by LCPC: ERM (elementary road modulus). The paper will also detail the assessment methodology using this same ERM method. The issues of resources conservation and waste allocation will be examined for the case of blast furnace slag (BFS) recycling. Special focus will be placed on the sensitivity of environmental indicators as regards to the waste allocation procedure implemented in the ERM. Two distinct mass ratios ( $0 \%$ and $20 \%$ ) of steel production have been assigned to BFS and tested on indicators results as hypotheses $\mathrm{H} 1$ and $\mathrm{H} 2$, respectively. Classical indicators have been calculated using a simplified model to allocate output flows into several impact categories. Results show that the structure using BFS contributes to saving binder extracted from natural resources, yet also consumes a larger mass of natural aggregates. All indicators except for toxicity were found to be very sensitive to the choice of $\mathrm{H} 1$ or $\mathrm{H} 2$ hypotheses.
\end{abstract}

(C) 2009 Elsevier B.V. All rights reserved.

\section{Introduction}

Road construction and maintenance represent the largest consumer of aggregates in France: some 200 million tonnes per year, composed essentially of alluvial and hard sedimentary and igneous rocks (UNPG, 2005). Opening and operating new quarries creates and may cause environmental damage, which makes them increasingly difficult to gain approval by the population.

In France's northern and eastern regions as well as in some foreign countries where the iron extraction industry has developed, blast furnace slag (BFS) has been used for a long time as an alternative material for road construction (OFRIR, 2008; Alexandre and Sebileau, 1998). The iron industry is able to generate two kinds of BFS, depending on the speed with the molten slag cools. Air-cooled (i.e. crystallized) BFS can be a good to very good quality aggregate (AFNOR, 1991a) with respect to road construction requirements for pavement (AFNOR, 2004) and earthworks (MELT, 2000). Quenched (i.e. vitrified) BFS displays hydraulic properties that serve to enhance road binders (AFNOR, 1991b); vitrified BFS can also be incorporated into cements (CEN, 2000). The charac-

\footnotetext{
* Corresponding author. Tel.: +332408456 16; fax: +332 40845993

E-mail address: anne.ventura@lcpc.fr (A. Ventura).
}

teristics and properties of vitrified BFS, in its use as a major road construction material in France, have been codified through a number of material standards (AFNOR, 1995a,b). For both technical and commercial reasons, the current production of BFS in France is primarily directed towards granulated BFS (François and Fantozzi, 2004).

For several years now (Hoang, 2005; Sayagh, 2007; Ventura et al., 2008a) LCPC has been designing a parametric environmental evaluation method called the elementary road modulus (ERM); this work has led to a tool developed by replicating the life cycle assessment (LCA) methodology and adapting it to road structure specificities. The purpose of ERM is to conduct global environmental evaluations (resource and energy consumption, assessment of emission releases and their environmental consequences) of road pavements as a function of materials (extraction, production, transport, properties), construction techniques (structure, consumption and discharges associated with machines), and maintenance policy. From an environmental impact perspective, ERM makes it possible to carry out comparisons between various construction techniques and/or choices of construction materials.

A beneficial use of alternative materials contributes both to reducing wastes and preserving natural resources. Moreover, the functionalities offered by ERM are particularly helpful in assessing 
the global environmental benefit of alternative material use in road construction. As regards BFS, results obtained allow measuring the sensitivity of environmental evaluation to the hypotheses of allocating environmental loads generated by their production process. Various approaches have already been proposed for the waste allocation step. On the one hand, BFS or any other useful waste can be considered as a recyclable output produced respectively by steel plants (Lee and Park, 2005) or any other production process (Finneveden et al., 2005). The open recycling loop is incorporated into the system extension method: environmental benefits induced by the substitution of natural resources for waste are subtracted from the environmental loads of waste producers (i.e. steel production for BFS). On the other hand (Buhé et al., 1997) proposed a method for allocating environmental benefits to the waste user. This article will seek to examine the variability in results for BFS recycling, by means of implementing within the ERM tool the two following extreme allocation procedures: (i) BFS is considered as steel plant waste, in which case no steel plant environmental flows are allocated to BFS (hypothesis H1) and (ii) BFS is considered as steel plant co-product, in which case $20 \%$ of the steel plant environmental flows are allocated to BFS based on the $\mathrm{BFS} /$ steel mass ratio (hypothesis $\mathrm{H} 2$ ).

The objective of this article therefore is to present the environmental evaluation of a flexible bituminous pavement built with granulated BFS (used as a binder in the base layer), along with a classical rigid pavement that includes steel bars (i.e. a reinforced concrete pavement). These products are referenced to a very classical bituminous flexible pavement using natural materials.

After presenting the ERM methodology based on LCA, this article will discuss the three under study as well as the calculation hypotheses. Assessment results will then be provided and commented.

\section{LCA framework of the ERM methodology}

The LCA methodology requires: (i) a description of the functional unit used as the basis for comparison, (ii) identification of environmental system boundaries, (iii) a list of the environmental data sources, and (iv) the choice of impact categories and indicators. All of these items will be described below as part of the ERM model constitutive framework.

\subsection{System boundaries}

The environmental system has been diagrammed in Fig. 1. The following processes are included within the environmental system boundaries: (i) manufacturing processes of main materials (crude oil extraction and refining plant for bitumen, cement plant, lime kiln, iron ore extraction, quarry for aggregates, steel plant and BFS conditioning process); (ii) material transports and road works equipment; (iii) mixing processes (cement and asphalt concrete plants); and (iv) road works processes (milling, paving and rolling).

A number of other processes have not been included in this system because of the assumption that they do not directly influence pavement structure comparison (i.e. such processes are presumed to be identical for each of the studied cases); these include: (i) energy production processes; (ii) buildings and all equipments used by staff; (iii) road-related safety and signaling equipment; and (iv) typical road maintenance operations (e.g. trench digging, de-icing, tree cutting).

Moreover, other processes have been excluded from the system since no reliable information could be found on them, these include: (i) aqueous and solid wastes storage, transports and treatments (given that the nature of wastes is not always known) and (ii) equipment production processes (i.e. factories and road works).

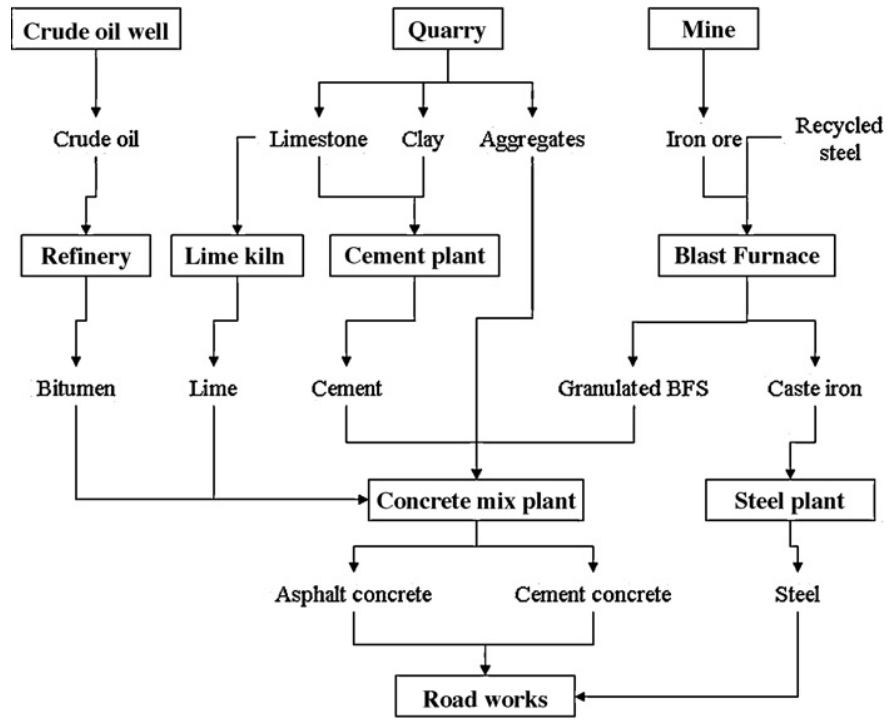

Fig. 1. Diagram of the environmental system.

\subsection{Data sources}

\subsubsection{Used life cycle inventory ( $L C I)$ data used}

Based on the selected system boundaries, a suitable dataset has been sought from the literature. Unfortunately, the author cited consider their system boundaries in accordance with their own objectives and at the scale of their particular processes, and these boundaries do not always correspond to the desired boundaries, as previously described in Fig. 1. Such differences pertain to inclusion of electrical energy production processes. In some cases, it is possible to deduct their contribution from the given data, but this is not so for all references. Furthermore, some authors consider that only generic data should be used, whereas others, (namely those in the field of civil engineering) produce local data tied to a given process.

Since the data itself is not the topic of the present paper, just a single reference has been chosen for each process. The selection procedure will be described next.

First of all, some processes have given rise to the publication of a large number of environmental reports. Generally speaking, the choice of references has been oriented towards preferring data appropriate for life cycle inventories (LCI) over environmental report data, which are not necessarily provided in a format suitable for $\mathrm{LCI}$, thus requiring calculations and assumptions for their successful adaptation. Among the various LCI data sources, the preference lies with references derived from aggregate data (i.e. the average of several industrial sites and technologies). For cement production, the data used stem from averages of several environmental data aggregated from various cement manufacturing plants in UK (Lafarge, 2005). Environmental data for bitumen production stem from (Blomberg et al., 1999), steel production from (IISI, 2002), and lime production and cement concrete mixing plant from (Stripple, 2001). For steel plants (IISI, 2002) electricity production has actually been included. As for BFS conditioning processes, only one reference was found (Vares and Häkkinen, 1998).

In other cases, local LCI data have been introduced; this would be the case for aggregate production in which a typical pavement production process had been incorporated (Martaud et al., 2007). Such is also the case for asphalt mix plants (Monéron et al., 2006) where LCI data from a current hot mix process (parallel flow drying drum fed with natural gas) were used.

Lastly, some of the data are not at all available for the following production processes of additives, fibres, tacking dope, emulsifying agents, fillers, stripping and curing products, resins, etc. 


\subsubsection{Data standardization for life cycle inventories}

References from the literature do not always use a standardized and exhaustive array of inventory flows. A standardization procedure has therefore proven necessary in performing the environmental evaluation. In particular, non-specific environmental data may be entered into some inventories, such as chemical or physical families, and chemical or biological tracers. This type of data is often encountered since it corresponds to systematic measurement imposed by regulation. Some data however have been excluded from the environmental database, due to the fact that their use in an indicator calculation would require more accurate chemical identification. Yet other data have been maintained in the final database when contributing a coefficient for at least one indicator.

\subsubsection{List of data held in the environmental database.}

- Airborne emissions of particles, dust, particulate matters, etc. have all been combined into a single inventory flow, labeled PM10 (for Particulate Matter less than $10^{-5} \mathrm{~m}$ ), since a contribution coefficient to toxicity already exists.

- The metals chemical family is vast and does not provide relevant information from the standpoint of indicators calculation. But excluding this data from inventories that use this family would be tantamount to assigning a penalty to inventories that provide better chemical speciation (e.g. chemical identification, oxidation degree). All inventory flows labeled "metals" have thus been assimilated to the most toxic metallic specie: chromium VI.

- The total nitrogen output flow, often written N-tot, accounts for the nitrogen present in organic compounds and ammoniac molecules, as well as oxidized nitrogen. The $\mathrm{N}$-tot contributes to eutrophication with an existing coefficient. Khjeldal nitrogen has been gathered with $\mathrm{N}$-tot.

- The total phosphorus output flow, often written P-tot, combines the phosphorus present in organic compounds with oxidized forms of phosphorus. The P-tot also contributes to eutrophication with an existing coefficient.

- The airborne volatile organic compounds (VOC) are defined as organic molecules in the gaseous phase at ambient temperature and pressure $\left(20-25^{\circ} \mathrm{C}\right.$, and atmospheric pressure). Methane is a VOC but is often excluded from counting, resulting in an abbreviation change to NMVOC (for non-methane VOC). Some inventories opt for the abbreviation HC for hydrocarbons, while others TOC for total organic carbons. All these chemical families have been collated under the heading NMGOC (for non-methane gaseous organic compounds), for which a contribution coefficient to photochemical ozone formation exists. To the greatest extent possible (should the data be given), methane is counted separately since it also contributes to greenhouse effect.

- The chemical oxygen demand (COD) is a chemical indicator and corresponds to the equivalent amount of oxygen necessary to oxidize organic matter (whether dissolved or not) into an aqueous solution. A contribution coefficient to eutrophication exists for COD.

\subsubsection{List of data not held the environmental database.}

- Oils are long-chained hydrocarbons that noneless offer numerous possible chemical structures.

- Particles emitted into water (also named particulate matter, dust, solid particles, etc.).

- Biological oxygen demand (BOD) is a biological indicator and corresponds to the equivalent amount of oxygen necessary to the biological decomposition of organic matter (whether dissolved or not) into an aqueous solution, within a given reference time- frame and at a given reference temperature (i.e. 5 days at $20^{\circ} \mathrm{C}$ for $\mathrm{BOD}_{5}$ ).

2.2.2.3. Missing data. One of the key questions raised by the use of alternative materials inside pavement layers relates to water leaching. Many laboratory tests have been conducted for materials (such as lixiviation), but they do not reflect the specific use focus within road layers when submitted to the aggressiveness of both traffic and climate. Although some studies were performed at full scale (François et al., 2009), the appropriate data for LCI are unavailable. Water emissions from pavements have thus not been included in this study.

\subsection{Impact indicators}

The calculation of impact indicators is described by the following formula:

$\operatorname{Ind}^{j}=\sum_{i} \alpha_{i}^{j} \cdot C_{i}^{j} \cdot m_{i}$

with Ind ${ }^{j}$ which is the indicator of impact category $j ; m_{i}$ is the mass of inventory flow $i(\mathrm{~kg}) ; C_{i}^{j}$ is the contribution coefficient of inventory flow $i$ to impact category $j$ (indicator unit per $\mathrm{kg}$ ); $\alpha_{i}^{j}$ is the allocation coefficient of inventory flow $i$ to impact category $\mathrm{j}$ (no unit).

\subsubsection{Indicators and sources of contribution coefficients}

The chosen impact categories and associated indicators are classical and have been extracted from the LCA literature:

- Energy consumption (EE), converted in MJ.

- Mass of consumed resources and materials.

- Global warming potential (GWP) from (IPCC, 2007).

- Acidification potential (AP) from (Goedkoop, 1996).

- Photochemical ozone creation potential (POCP) from (Goedkoop, 1996).

- Eutrophication index (EI) from (Goedkoop, 1996).

- Toxic and ecotoxic potentials (TP and EP) from (Huijbregts et al., 2000).

\subsubsection{Allocation coefficients}

The allocation coefficient yields, for a given inventory flow, the mass proportion contributing to a given impact category. This coefficient is used when one inventory flow is capable of contributing to several impact categories. A simplified methodology (Ventura et al., 2008b) has been developed to calculate these coefficients and is schematised in Fig. 2.

The mass ratio of one pollutant between several impact categories depends on: (i) the type of pathway a single molecule needs to follow in order to contribute to several impact categories; (ii) the emission site, and in particular the presence or absence of the target exposed to the environmental impact; (iii) the environmental medium (air, water, soil) receiving the emission that influences the area of impact.

Fig. 2 gives the allocation procedure for $\mathrm{HCl}, \mathrm{HF}, \mathrm{SO}_{2}$ and $\mathrm{NO} x$. All of these compounds can contribute to acidification, photochemical ozone formation and toxicity. Their contribution to these three impacts is exclusive (i.e. a given molecule can only contribute to one impact at a time). Two types of processes responsible for these emissions were distinguished:

- Diffuse emissions are considered to contribute preferentially to toxicity, because emitted close to population centers at low altitudes (below $2 \mathrm{~m}$ ). Allocation to the toxicity impact category was arbitrary set at $50 \%$. The remaining $50 \%$ contribute to both 


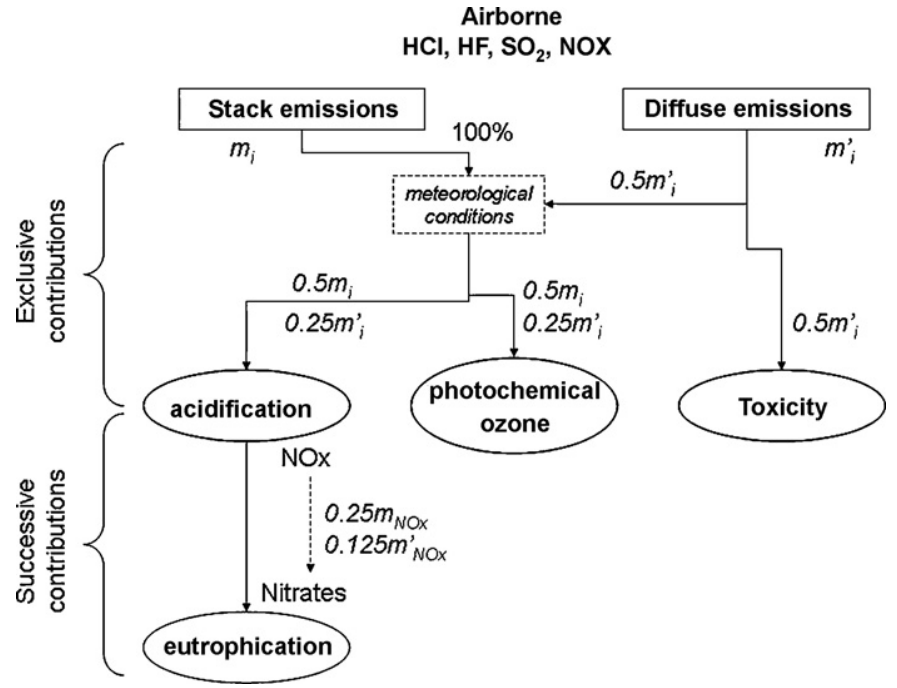

Fig. 2. Flowchart of the procedure employed to determine allocation coefficients for output flows contributing to several impact categories $\left(\mathrm{i}=\mathrm{HCl}, \mathrm{HF}, \mathrm{SO}_{2}\right.$ or $\left.\mathrm{NOx}\right) . m_{i}$ : masse of pollutant $i$ emitted at the stack. $m_{i}^{\prime}$ : mass of pollutant $i$ diffusively emitted.

acidification and photochemical ozone formation, depending on meteorological conditions. With dry and warm weather, photochemical ozone formation is favored, whereas acidification tends to accompany wet weather. It was arbitrarily considered that under European temperate climate, pollutants would contribute to both impact categories at a 50/50 mass ratio.

- Stack emissions are considered not to contribute to toxicity at all. Otherwise, the distribution of pollutants between acidification and photochemical ozone formation follows the same pattern as presented above.

Lastly, in the case of NOx, a contribution to eutrophication impact was considered to occur subsequent to acidification, because according to that phenomenon, $\mathrm{NO} x$ is dissolved into rainwater. It was arbitrarily considered that $50 \%$ of the NOx contributing to acidification would further contribute to eutrophication.

Successive contributions also concern airborne $\mathrm{CH}_{4}$ emissions that contribute immediately to the greenhouse effect and then to photochemical ozone formation when degraded at low altitudes under the effect of sunrays. $100 \%$ of $\mathrm{CH}_{4}$ was therefore allocated to the greenhouse effect, and $50 \%$ then assigned to photochemical ozone formation.

Table 1 has summarized allocation coefficients by both molecule and process. Refining plant, asphalt mixing plant, steel plant, lime kiln and cement plant were all considered to mainly produce stack emissions. Quarries, road works, transports and cement mixing plant were considered to essentially produce diffuse emis- sions (for the most part from heat engines installed in trucks and equipment).

\section{Studied pavement structures and calculation hypotheses of the ERM model}

The pavement life cycle can be summarized in three main steps: initial construction, pavement operations, and end-of-life cycle. Various LCA studies published on road pavements have introduced different hypotheses, as described in Table 2, which highlights the tremendous variety of possible input hypotheses. The ERM tool allows for parameterization of such hypotheses. ERM only accounts for the construction and structural maintenance of pavements however, and the end-of-life stage has not included, since this stage is indeed considered unusual in European countries.

\subsection{Road initial construction and maintenance}

Three distinct pavement structures have been chosen from national guidelines (SETRA/LCPC, 1998): two use classical materials, while the third uses BFS. They are shown in Fig. 3 as: (i) case $a$ is a flexible bituminous pavement (GB); (ii) case $b$ is a rigid reinforced concrete (RC) pavement; and (iii) case $c$ is a semi-rigid gravel-slag (GS) mixture pavement.

All three structures have been selected in order to satisfy the following initial conditions:

- They are built on a PF2 platform according to the (SETRA/LCPC, 1998 ) classification (modulus of elasticity $\geq 50 \mathrm{MPa}$ ),

- They authorize an identical TC6 class of traffic according to the (SETRA/LCPC, 1998) classification (9.4 million trucks per lane cumulated over 30 years).

- They are calculated over a 30-year service period.

- Lane width is set at $3.5 \mathrm{~m}$ and pavement length at $1 \mathrm{~km}$.

The pavements structure maintenance policy from Fig. 3 have been extracted from the (SETRA/LCPC, 1998) guidelines, for a 30year service life; it has been diagrammed in Table 3 . The time column provides the number of years after initial construction. The maintenance operation is briefly indicated in other columns for each structure. Prior to the paving operations described in Table 3, the previous layer is systematically milled at the thickness required for the new layer.

\subsection{Materials and processes}

The list of materials and corresponding manufacturing processes has been included in Fig. 3. The composition of each pavement material has been selected according to (SETRA/LCPC, 1998) and given in Table 4. Reinforced concrete (RC), cement

Table 1

Allocation coefficients by molecule, impact category and process.

\begin{tabular}{|c|c|c|c|c|}
\hline \multirow[t]{2}{*}{ Process } & \multirow[t]{2}{*}{ Impact category } & \multicolumn{3}{|c|}{ Airborne emissions } \\
\hline & & $\mathrm{CH} 4$ & $\mathrm{HCl}, \mathrm{HF}, \mathrm{SO} x$ & $\mathrm{NO} x$ \\
\hline \multirow[t]{5}{*}{ Refining plant, asphalt mixing plant, steel plant, lime kiln, cement plant } & Greenhouse effect & 1 & 0 & 0 \\
\hline & Tropospheric ozone creation & 0.5 & 0.5 & 0.5 \\
\hline & Acidification & 0 & 0.5 & 0.5 \\
\hline & Eutrophication & 0 & 0 & 0.25 \\
\hline & Toxicity & 0 & 0 & 0 \\
\hline \multirow[t]{5}{*}{ Quarry, road works, cement mixing plant, transports } & Greenhouse effect & 1 & 0 & 0 \\
\hline & Tropospheric ozone creation & 0.5 & 0.25 & 0.25 \\
\hline & Acidification & 0 & 0.25 & 0.25 \\
\hline & Eutrophication & 0 & 0 & 0.12 \\
\hline & Toxicity & 0 & 0.5 & 0.5 \\
\hline
\end{tabular}




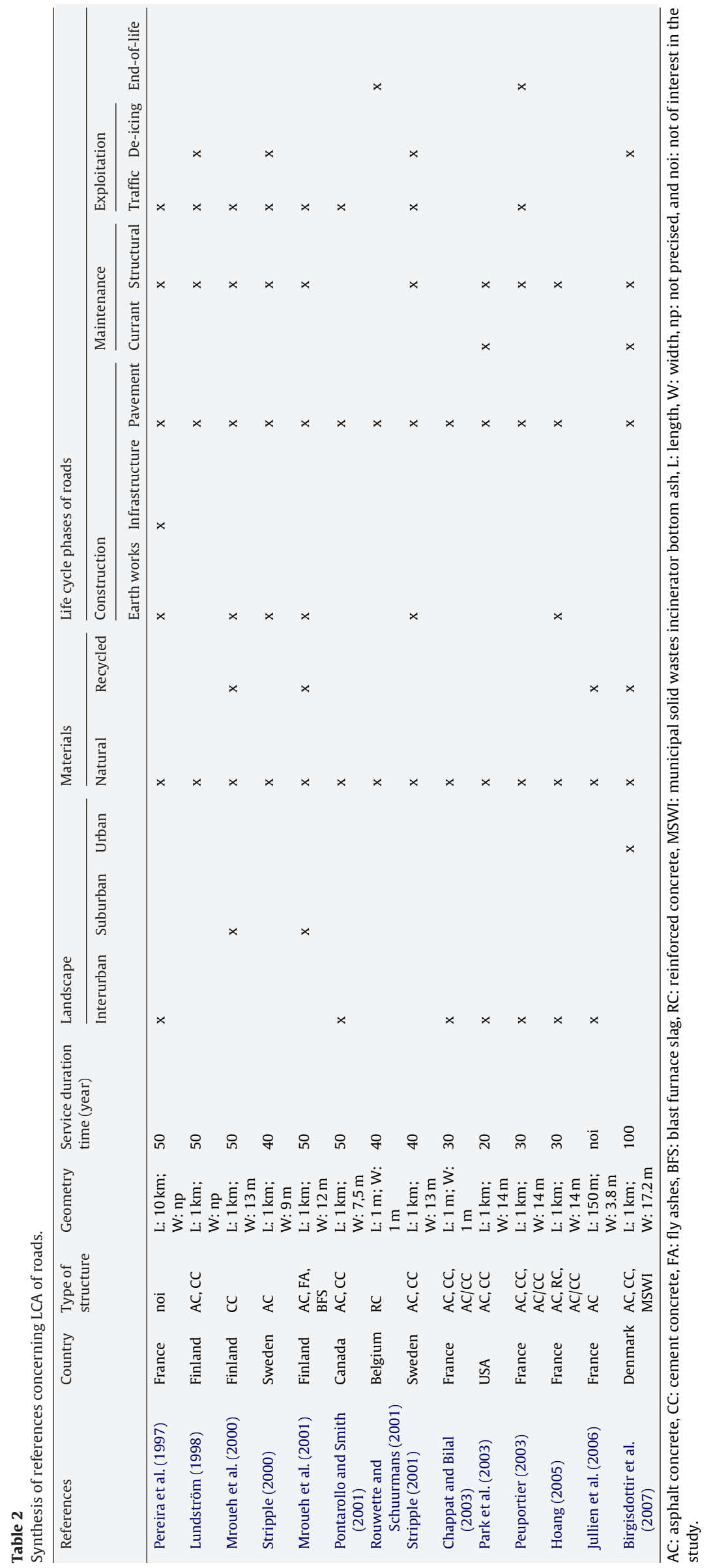


(a) Bituminous pavement

\begin{tabular}{|c|}
\hline SA $(2.5 \mathrm{~cm})$ \\
\hline$A C S G(6 \mathrm{~cm})$ \\
\hline GB $(13 \mathrm{~cm})$ \\
\hline GB (13 c m) \\
\hline
\end{tabular}

\section{SA Sheet Asphalt \\ ACSG Asphalt Concrete Semi Grema}

(b) Concrete pavement

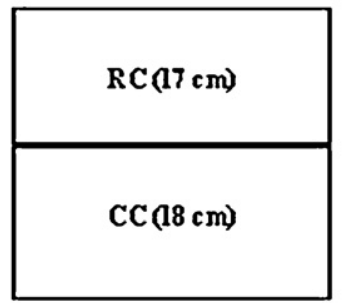

RC Reinforced Concrete

CC Cement Concrete (c) Slag pavement

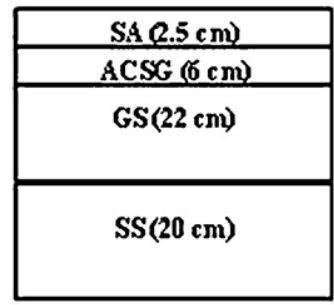

GS Grave Slag mixture

SS Sand Slag mixture

\section{GB Gravel stabilised with Bitumen}

Fig. 3. Pavement structures of the studied cases.

Table 3

Policy pavement maintenance.

\begin{tabular}{|c|c|c|c|}
\hline Time (year) & $\begin{array}{l}\text { (a) } \\
\text { GB/GB }\end{array}$ & $\begin{array}{l}\text { (b) } \\
\mathrm{RC} / \mathrm{CC}\end{array}$ & $\begin{array}{l}\text { (c) } \\
\text { GS/SS }\end{array}$ \\
\hline 8 & & $100 \%$ SA $2.5 \mathrm{~cm}$ & $60 \%$ AC $4 \mathrm{~cm}+40 \%$ AC $8 \mathrm{~cm}$ \\
\hline 9 & $60 \% A C 4 \mathrm{~cm}+40 \% A C 8 \mathrm{~cm}$ & & \\
\hline 12 & & $50 \% \mathrm{SA} 2.5 \mathrm{~cm}$ & \\
\hline 15 & & $50 \%$ SA $2.5 \mathrm{~cm}$ & \\
\hline 16 & & & $60 \% \mathrm{AC} 4 \mathrm{~cm}+40 \% \mathrm{AC} 8 \mathrm{~cm}$ \\
\hline 17 & $60 \% \mathrm{AC} 4 \mathrm{~cm}+40 \% \mathrm{AC} 8 \mathrm{~cm}$ & & \\
\hline 19 & & $50 \% \mathrm{SA} 2.5 \mathrm{~cm}$ & \\
\hline 24 & & & $60 \%$ AC $4 \mathrm{~cm}+40 \%$ AC $8 \mathrm{~cm}$ \\
\hline 25 & $60 \% A C 4 \mathrm{~cm}+40 \% A C 8 \mathrm{~cm}$ & $100 \% \mathrm{SA} 2.5 \mathrm{~cm}$ & \\
\hline 30 & $37 \% \mathrm{AC} 4 \mathrm{~cm}+25 \% A C 8 \mathrm{~cm}$ & $100 \% \mathrm{RC} 20 \mathrm{~cm}$ & $45 \%$ AC $4 \mathrm{~cm}+30 \%$ AC $8 \mathrm{~cm}$ \\
\hline
\end{tabular}

RC: reinforced concrete, CC: cement concrete, GB: gravel stabilized with bitumen, GS: gravel-slag mixture, SS: sand-slag mixture, SA: sheet asphalt, AC: asphalt concrete.

" $x \%$ ": pavement surface area that is renewed, " $y \mathrm{~cm}$ ": thickness of old layer that is milled and thickness of new layer (in cm).

concrete (CC), gravel-slag (GS) and sand-slag (SS) are produced from cement concrete mixing plants, while sheet asphalt (SA), asphalt concrete semi-grenu (ACSG) and gravel bitumen (GB) are produced at asphalt mixing plants. These two processes use several input materials, the most common of which are indicated below:

- Aggregates: these can be either natural (when extracted from quarries) or recycled (when output from industrial by-products or wastes). Their mass proportion varies between $80 \%$ and approximately $95 \%$ of the total material mass;

- binders: these can be made of either bitumen or cement. The bitumen mass proportion varies roughly from $3 \%$ to $6 \%$, while cement content ranges between $4 \%$ and $16 \%$, depending on the type of layer. Bitumen is produced from refined crude oil, and the cement is basically obtained from heating a mix of lime and clay, yet components may also include significant proportions of recycled industrial wastes such as granulated BFS or fly ash;

- steel rebar: in some cases, rebar is added to reinforce the cement concrete. Steel is made from iron ore and recycled scrap steel (IISI, 2002);

- chemical additives: these are used in small proportions in order to obtain specific mechanical properties during the construction process, and/or throughout the lifetime of the road layer.

\subsection{Transport-related hypotheses}

Materials and equipment are assumed to be transported solely by semitrailer. Transport distances have been calculated from

\section{Table 4}

Compositions of pavement materials.

\begin{tabular}{|c|c|c|c|c|c|c|c|}
\hline \multicolumn{4}{|l|}{ Pavement structure cases } & \multicolumn{4}{|l|}{ (c) } \\
\hline \multirow[b]{2}{*}{ Components } & \multicolumn{2}{|l|}{ (b) } & \multicolumn{3}{|l|}{ (a) } & \multirow[b]{2}{*}{ GS } & \multirow[b]{2}{*}{ SS } \\
\hline & $\mathrm{RC}$ & $\mathrm{CC}$ & GB & SA & ACSG & & \\
\hline Sand $0 / 5(\mathrm{~kg})$ & 800 & 860 & & & & & \\
\hline Aggregates $\left(\mathrm{kg} / \mathrm{m}^{3}\right)$ & & & 2372 & 2298 & 2305 & 2302 & 2451 \\
\hline Gravel 5/10 (kg) & 440 & & & & & & \\
\hline Gravel 5/25 (kg) & & 935 & & & & & \\
\hline Gravel 10/20(kg) & 585 & & & & & & \\
\hline Plastifying agent $(\mathrm{kg})$ & 1.65 & 1.25 & & & & & \\
\hline Air entraining agent (kg) & 0.06 & 0.025 & & & & & \\
\hline Cement CEMII/A 32.5 (kg) & 325 & 250 & & & & & \\
\hline Water $(\mathrm{L})$ & 145 & 170 & & & & 161 & 171 \\
\hline Bitumen in formula $\left(\mathrm{kg} / \mathrm{m}^{3}\right)$ & & & 108 & 137 & 134 & & \\
\hline Bitumen for stick layer $\left(\mathrm{kg} / \mathrm{m}^{2}\right)$ & & & 0.250 & 0.250 & 0.250 & & \\
\hline Granulated BFS $\left(\mathrm{kg} / \mathrm{m}^{3}\right)$ & & & & & & 375 & 399 \\
\hline Lime $\left(\mathrm{kg} / \mathrm{m}^{3}\right)$ & & & & & & 27 & 29 \\
\hline
\end{tabular}


Table 5

Description of transport scenario.

\begin{tabular}{lllr}
\hline Goods & Initial spot & Destination spot & Distance $(\mathrm{km})$ \\
\hline BFS & Development platform & Road works site & 50 \\
Lime & Lime kiln & Road works site & 173 \\
Aggregates & Quarry & Mixing plant & 38 \\
Cement & Cement works & Concrete mixing plant & 152 \\
Bitumen & Refinery & Mixing plant & 333 \\
Steel & Steel works & Road works site & 500 \\
Cement or asphalt concrete & Mixing plant & Road works site & 21 \\
Road works equipment & Storage centre & Road works site & Semi-trailer \\
\hline
\end{tabular}

the average distances found in other references: (Mroueh et al., 2000), (Stripple, 2001), (Pontarollo and Smith, 2001), (CEN, 2000), (Rouwette and Schuurmans, 2001), (Chappat and Bilal, 2003) and (UNPG, 2005). All of the pertinent transport hypotheses are listed in Table 5.

\section{Results}

\subsection{Materials and energy resource consumption}

Table 6 presents the masses of materials consumed or generated by each of the cases studied. It should be observed that in all cases, reclaimed asphalt pavement (RAP) is produced, and this is due to the renovation of upper pavement layers (detailed previously in Table 3).

Fig. 4a-c illustrates the trends obtained in the consumption of binder, aggregate, water and steel. Fig. 4a shows a comparison between the masses and types of binders used to build the three structures under study. Some of the bitumen has been consumed by cases (a-GB), (b-RC) and (c-GS), with higher consumption for case $a$. Only cement is consumed in case $b$ whereas vitrified BFS and lime are consumed in case $c$, which also happens to consume the highest total binder mass. However, $60 \%$ of this total mass corresponds to granulated BFS, meaning that the mass of materials stemming from natural resources is lower. The consumption of natural aggregate is shown in Fig. 4b. The lowest consumption level is obtained by case (b-RC), while the highest is associated with the case (c-GS). As displayed in Fig. 4c, water is consumed by both cases (b-RC) and (c-GS), and steel solely in case (b-RC).

The net consumption of bitumen and aggregates resources is given in Fig. 4d. RAP is indeed easily and often recycled into new asphalt concrete, hence, they can be considered as new resources. If RAP is all recycled further and contain roughly $5 \%$ bitumen and $95 \%$ aggregate, new resources of recycled bitumen and recycled aggregate could thus be calculated and subtracted from the bitumen and aggregate consumption figure. For net bitumen consumption, results indicate the same ranking between the three cases as found in Fig. 4a. For net aggregates consumption, case (c-GS) remains the highest consumer as compared with Fig. $4 \mathrm{~b}$, but the ranking between cases (a-GB) and (b-RC) becomes reversed.

Moreover, the energy consumption for each studied case is shown in Fig. 4e. The results depict two different allocation procedures (hypotheses $\mathrm{H} 1$ and $\mathrm{H} 2$ ) of steel plant contribution, i.e. between steel and BFS. Cases (a-GB), (b-RC) and (c-GS) reveal different distributions of energy consumption from one process to the next. For case (a-GB), bitumen refining and asphalt concrete mixing plant are found to be the main contributors to energy consumption. For case (b-RC), steel and cement plants have this distinction. For case (c-GS) the bitumen refining plant and the BFS production are responsible for the majority of energy consumption. Results are determined to be very sensitive to both $\mathrm{H} 1$ and $\mathrm{H} 2$ hypotheses: for case (b-RC), the contribution of steel production to energy consumption is slightly lower, whereas for case (c-GS), energy consumption is more than twice as high with $\mathrm{H} 2$ compared to $\mathrm{H} 1$.

\subsection{Environmental impact indicators}

The environmental impacts indicators calculated for the three pavement structures are presented in Fig. $5 \mathrm{a}-\mathrm{f}$.

The global warming potential (GWP) is shown in Fig. 5a. The main contributing processes are roughly the same as those observed previously for energy consumption, with a more significant contribution from steel plant and lime kiln processes. Due to the cement plant contribution, case (b-RC) is found to be the greatest contributor to greenhouse effect, regardless of whether the H1 or $\mathrm{H} 2$ hypothesis has been adopted. Case (c-GS) is still found to be very sensitive to both $\mathrm{H} 1$ and $\mathrm{H} 2$ hypotheses, with contribution increase of roughly $60 \%$.

The photochemical ozone creation potential (POCP) is provided in Fig. 5b. This indicator value ranges from 250 to $350 \mathrm{~kg}$ equiv. ethylene in all cases. Refining, cement and steel plants constitute

Table 6

Masses of materials used for pavement construction and maintenance (reduced to $1 \mathrm{~km}$ and a sense of movement over 30 years).

\begin{tabular}{|c|c|c|c|c|}
\hline & & $\begin{array}{l}\text { (a) } \\
\mathrm{GB} / \mathrm{GB}\end{array}$ & $\begin{array}{l}\text { (b) } \\
\mathrm{RC} / \mathrm{CC}\end{array}$ & $\begin{array}{l}\text { (c) } \\
\text { GS/SS }\end{array}$ \\
\hline \multirow[t]{3}{*}{ Pavement mixtures } & Total asphalt concrete (tonnes) & 4703 & 746 & 2518 \\
\hline & Total cement concrete $\left(\mathrm{m}^{3}\right)$ & 0 & 1925 & 0 \\
\hline & Total Grave BFS mixture (tonnes) & 0 & 0 & 3931 \\
\hline \multirow[t]{7}{*}{ Rough materials for pavement mixtures } & Steel (tonnes) & 0 & 70 & 0 \\
\hline & Bitumen (tonnes) & 380 & 109 & 291 \\
\hline & Cement (tonnes) & 0 & 578 & 0 \\
\hline & Aggregates (tonnes) & 4482 & 4198 & 746 \\
\hline & Granulated BFS (tonnes) & 0 & 0 & 499 \\
\hline & Lime (tonnes) & 0 & 0 & 40 \\
\hline & Water $\left(\mathrm{m}^{3}\right)$ & 0 & 295 & 236 \\
\hline Generated materials & RAP (tonnes) & 1912 & 746 & 1767 \\
\hline
\end{tabular}

RC: reinforced concrete, CC: cement concrete, GB: gravel stabilized with bitumen, GS: gravel-slag mixture, SS: sand-slag mixture. 


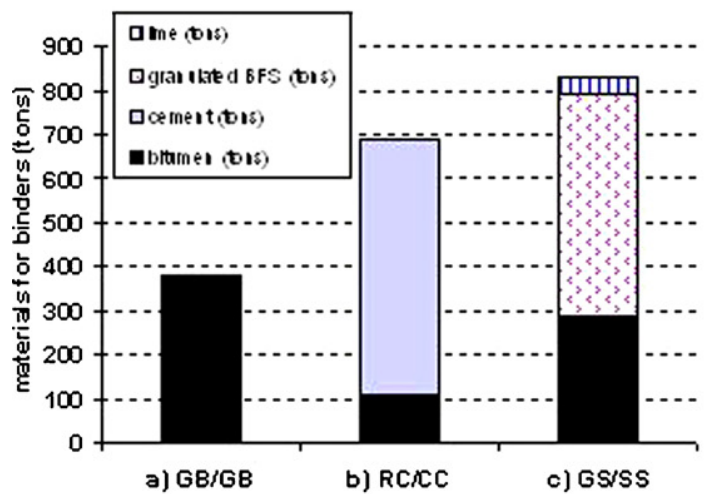

a. Consumed materials for binders (tons)

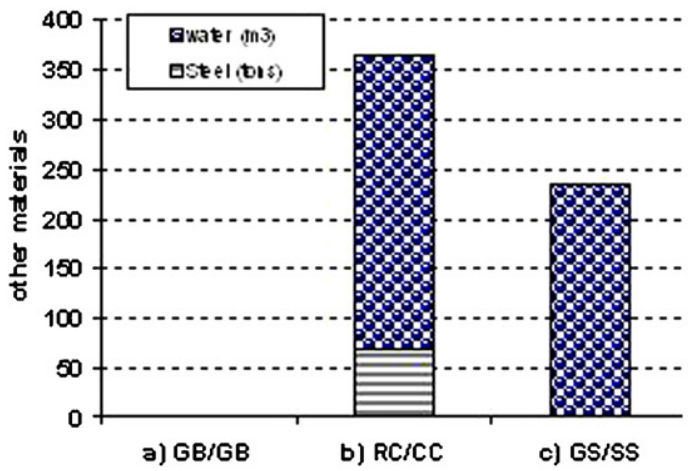

c. Other consumed materials

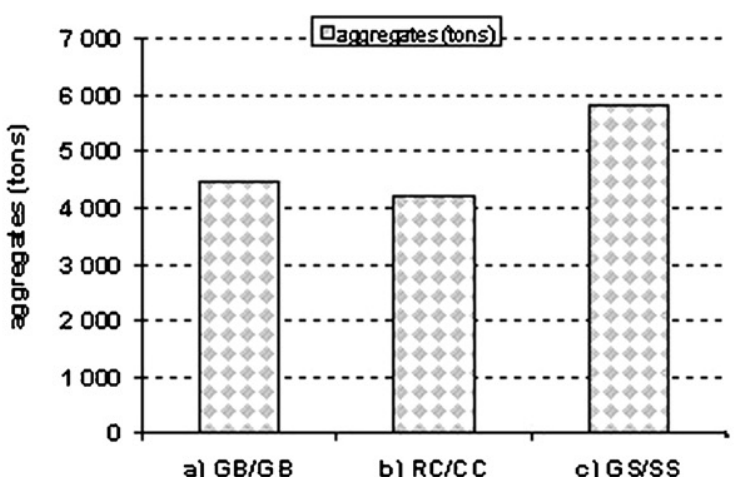

b. Consumed materials for aggregates (tons)

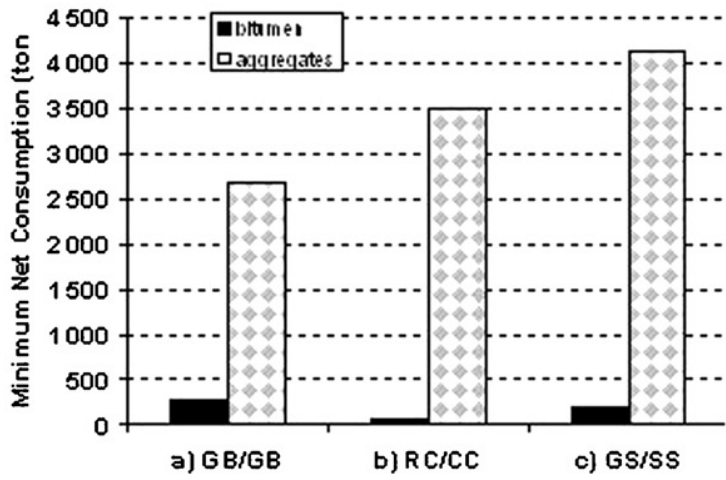

d. Bitronen and aggregates net consumptions if $100 \%$ of $R A P$ prodised during maintenance oper ations were recycled, and asszoming these RAP contain $5 \%$ bitomen

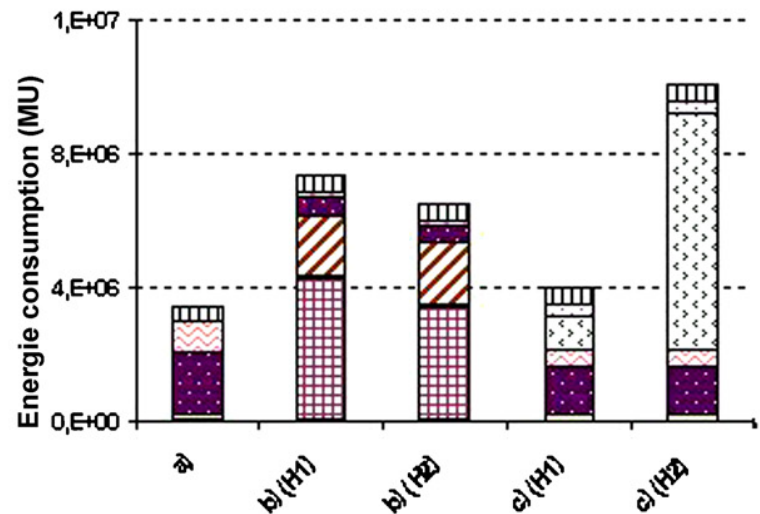

e. Energy consumption

Fig. 4. Masses of consumed materials for $1 \mathrm{~km}$ of 1 lane over 30 years. RAP: reclaimed asphalt pavement and BFS: blast furnace slag. (a) Consumed materials for binders (tonnes), (b) consumed materials for aggregates (tonnes), (c) other consumed materials, (d) bitumen and aggregates net consumptions if $100 \%$ of RAP produced during maintenance operations were recycled, and assuming these RAP contain 5\% bitumen, and (e) energy consumption.

its main contributing processes. For the $\mathrm{H} 2$ hypothesis, the BFS production process is found to have increased drastically, causing a $25 \%$ rise in total compared to $\mathrm{H} 1$.

The acidification potential (AP) and eutrophication index (EI) appear respectively on Fig. $5 \mathrm{c}$ and d. For both of these indicators, the ranking between cases and processes contributions is determined to be similar to the GWP indicator (see Fig. 5a), with the cement plant being the largest contributor. For both indicators and case
(c-GS), the $\mathrm{H} 2$ hypothesis generates a $25 \%$ increase in comparison with $\mathrm{H} 1$.

The toxic potential (TP) is shown in Fig. $5 f$ and only concerns bitumen production: the refining plant is definitely the major contributor for this indicator. Case (a-GB) is therefore considered the most sizable contributor to TP indicator, i.e. three times greater than case (b-RC) and case (c-GS) results are not found sensitive to $\mathrm{H} 1$ and $\mathrm{H} 2$ hypotheses. 


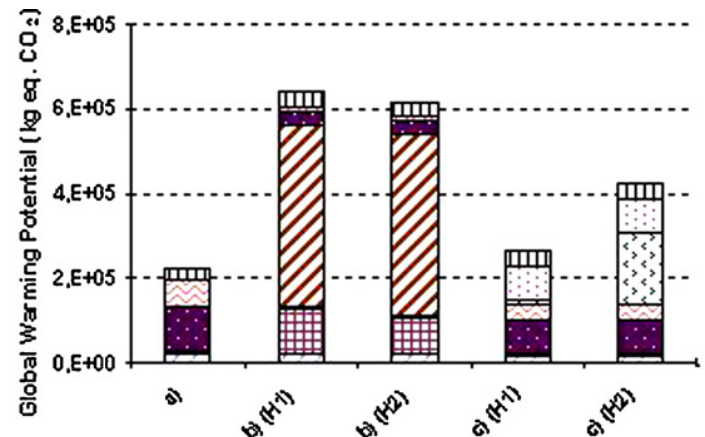

(a)

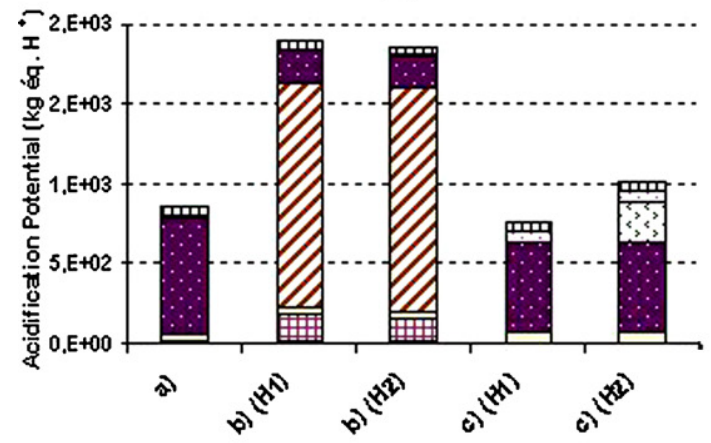

(c)

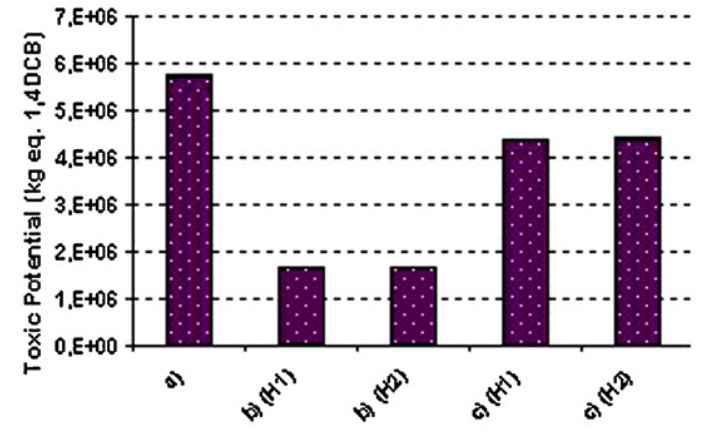

(e)

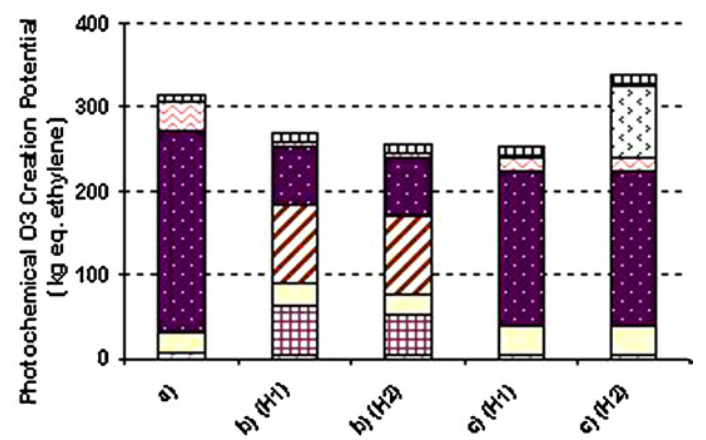

(b)

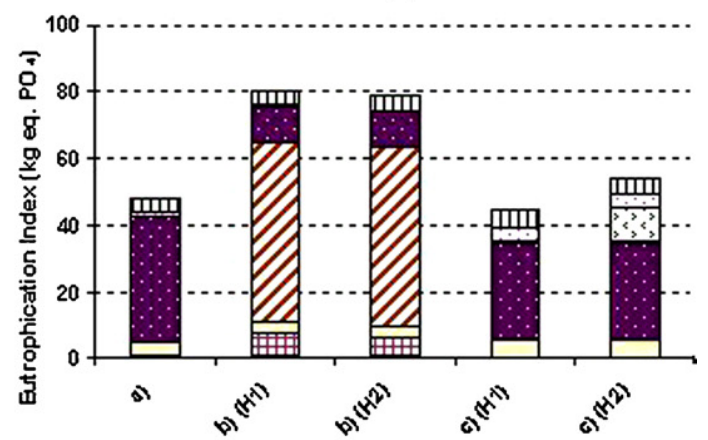

(d)

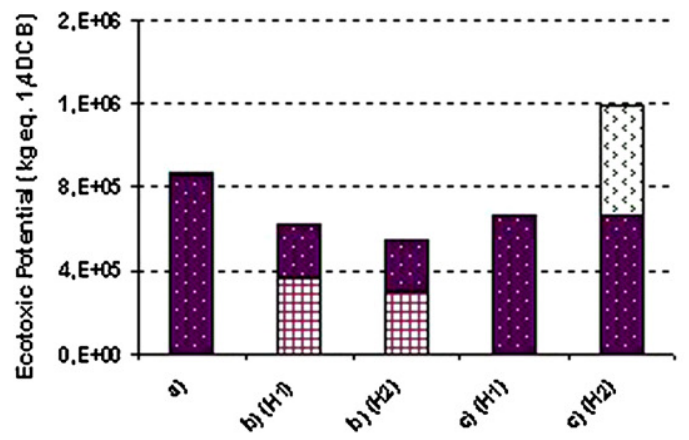

(f)

\begin{tabular}{|c|}
\hline Legend \\
\hline ए transport \\
\hline Dlime \\
\hline Evitrified BFS \\
\hline$\square$ granulated BFS \\
\hline$\square$ cement concrete mixing plant \\
\hline$\square$ asphalt concrete mixing plant \\
\hline refining plant \\
\hline$\square$ cement plant \\
\hline$\square$ quarry \\
\hline ⿴囗十 steel plant \\
\hline
\end{tabular}

Fig. 5. Environmental indicators for each studied case (1 km, 30 years, 1 lane).

The ecotoxic potential (EP) is indicated in Fig. 5g. Its major contributions stem from bitumen refining and steel plants. Since steel plants are heavily contributing to this indicator, case (c-GS) is therefore found very sensitive to $\mathrm{H} 1$ and $\mathrm{H} 2$ hypotheses.

\section{Discussion}

The ERM method is a specific method for the environmental assessment of pavement structures; it is well adapted to the level of modularity required in the road construction field, where a wide range of technical solutions may correspond to initial traffic and earth platform conditions. This method is appropriate when including recycled materials and accounting for natural resource savings. Our paper however has also highlighted the main limitations associated with this method.

The first such limitation concerns the issue of environmental data. On the one hand, the quality of published data influences system boundaries. Several references make use of extended 
boundaries in comparison with the present targeted ones. Should the data provided in these references lack sufficient detail, the contributions from undesired processes cannot be subtracted. Using these data leads to the ability to fit into the system boundary definition. On the other hand, data heterogeneity between various references exerts a direct influence on indicators values. A process associated with a reference that provides highly detailed environmental data will invariably be revealed in the results, as opposed to a process whose reference offers just limited data. This lack of data may sometimes be compensated by using pessimistic hypotheses, i.e. in the present study by assuming "total metals" to be equivalent to "Cr VI". Yet this procedure is far from satisfactory and discrepancies between processes in that case become unavoidable. Apart from resources consumption results, attention should be more heavily focused on trends rather than on the absolute values of other indicators results. A comparison of pavement structures is still not considered to be completely reliable.

In focusing on results, natural resource consumptions can be commented from an examination of Table 6 and Fig. 4. The consumptions of binders derived from natural resources are obviously found to be higher for cases (a-GB) and (b-RC), given that (c-GS) uses recycled BFS as a binder. The consumption of natural aggregates however proves to be higher for case (c-GS) than for the other two cases. This result is directly correlated with layer thickness (Fig. 3) and thus to the choice of pavement structure case. French guidelines recommend setting a higher value for case (c-GS) than for (a-GB) and (b-RC), in order to attain a similar mechanical performance. Nevertheless, considering that all RAP is further recycled (Fig. 4d) leads to reversing the ranking between cases (a-GB) and (b-RC) for aggregate consumption; moreover, the pavement structure defined in case (c-GS) remains the greatest natural aggregate consumer.

An analysis of indicator results leads to a classification into several categories that depend on the major contributing manufacturing processes, some of which are more specific to one of the studied cases, i.e. cement and steel plants for case (b-RC), and BFS production and lime kiln for (c-GS). On the other hand, some processes are necessary for all cases, i.e. aggregate production, refining plant and transport. When cement or steel plants is responsible for a significant contribution to one of the indicators, case (b-RC) is thus found to exceed cases (a-GB) and (c-GS). Case (b-RC) is therefore determined to contribute more than the other two towards the greenhouse effect (Fig. 5b), acidification (Fig. 5d) and eutrophication (Fig. 5e). Furthermore, a high contribution from the steel plant process leads not only to focusing on case (b-RC), but also emphasizes case (c-GS) whenever the steel plant and the BFS production processes are tied by means of the $\mathrm{H} 2$ hypothesis. This finding is especially obvious for the energy consumption (Fig. 5a), photochemical ozone (Fig. 5c) and ecotoxicity (Fig. 5g) indicators. In addition, the refining plant is determined to be just about the only contributor to toxicity (Fig. 5f) indicator, with results found to be directly proportional to the quantity bitumen mass consumption (Table 6).

\section{Conclusion}

The purpose of this study has been to analyze the sensitivity of environmental evaluations of road pavements to the waste allocation procedure implemented as part of the ERM tool (which is an LCA-based method specially developed for this type of infrastructure). Three cases of typical pavement, of which structures follows the official French guidelines, have been studied: one structure (aGB) representing the comparative reference as a typical choice, a second structure (b-RC) using steel and one last one (c-GS) using recycled granulated BFS. The ERM tool was implemented under two extreme waste allocation hypotheses, one corresponding to the waste user (H1: BFS can be considered as steel plant waste, with none of the steel plant environmental flows allocated to BFS); and the other corresponding to the wastes user (H2: BFS can be considered as steel plant co-product, in which case $20 \%$ of the steel plant environmental flows are allocated to BFS on the basis of the $\mathrm{BFS} /$ steel mass ratio).

It should be recalled that all results are highly dependent on the availability and quality of environmental data in the literature. Any global comparison, such as the present one, can only lay out general trends, but should not be considered as accurate and definitive.

Results indicate that for identical mechanical requirements, the (c-GS) structure with BFS not only contributes to conserving binder produced from natural resources, but also consumes a higher mass of natural aggregates. This result is entirely correlated with the chosen pavement structure case. Since each pavement is unique, providing decision-makers with environmental guidance necessitates examining each particular case within its own geometry.

Indicators results are found to be extremely sensitive to the adopted hypothesis $\mathrm{H} 1$ or $\mathrm{H} 2$, for most of the calculated indicators values: in selecting H2, i.e. the waste producer's point of view, the decision-maker, who is the potential waste user, would likely be led to rejecting the (c-GS) structure, even though it contributes to BFS recycling. The LCA methodological choices for wastes allocation extend beyond the scientific domain and may entail significant political implications. The sensitivity of these choices should be systematically explored and commented within the framework of future decisions. ERM has proven to be a suitable tool for performing such a parametric study.

\section{Acknowledgments}

Since 2002, the development of environmental evaluation tools has been undertaken in partnership with LET (Transport Economics Laboratory, Lyon) and CETE Public Works Study Center based in Nantes. A portion of this work has been the topic of a Ph.D. study co-funded by ADEME (France's Environment and Energy Agency) and LCPC. The authors would like to express special thanks to Mr. Chateau from ADEME for his Agency's financial support.

\section{References}

Association Française de Normalisation. Aggregate-crystallized blast furnace slag. P98-302 standard; 1991a.

Association Française de Normalisation. Road foundations-activation of vitrified slag-definition, characteristics and speciation. NF P98-107 standard; 1991b.

Association Française de Normalisation. Roadway foundation-vitrified blast furnace slag (granulated or pelletized)-determination of the activity coefficient. XP P 18-109 standard; 1995a.

Association Française de Normalisation. Roadway foundation-vitrified blast furnace slag (granulated or pelletized)-determination of the coarse breaking class. XP P 18-109 standard; 1995b.

Association Française de Normalisation. Aggregates-defining elements, conformity and coding. XP P 18-545 experimental standard; 2004.

Alexandre J, Sebileau JL. 1998. Les Laitiers de haut fourneau: elaboration, traitements, propriétés, emplois Ed. Paris: CTPL; 1988.

Birgisdottir $\mathrm{H}$, Bhander G, Hauschild MZ, Christensen TH. Life cycle assessment of disposal of residues from municipal solid waste incineration: recycling of bottom ash in road construction of landfilling in Denmark evaluated in the ROAD-RES model. Waste Manage 2007;27:S75-84.

Buhé C, Achard G, Le Téno JF, Chevalier J-L. Integration of the recycling processes to the life cycle analysis of construction products. Res Cons Recycl 1997:20:227-43.

CEN, European Normalisation Committee. Cement-Part 1. Composition, specifications and conformity criteria for common cements. EN 197-1 standard; 2000.

Cimbéton, Peuportier B. Analyse de vie d'un kilomètre de route et comparaison de six variantes. Report from Centre d'Energétique de l'Ecole de Mines de Paris Ed. Paris: CIMbéton; 2003.

Colas, Chappat M, et Bilal J. La route écologique du future-Consommation d'énergie \& émission de gaz à effet de serre. Report Ed. by COLAS Cie; 2003. Available online: http://www.colas-cst.com/documents/publications/2003.pdf.

Blomberg T, Boussad N, Coronado J, De Jonghe T, Ekström LG, Herment R, Holtken G, Lecouls H, Muller A, Thomas M, Watkins S. Partial life cycle inventory or "ecoprofile" for paving grade bitumen. Report 99/007 Ed. by the European Bitumen Association, Brussels; 1999. 
Finneveden G, Johansson J, Lind P, Moberg A. Life cycle assessment of energy from solid waste-Part 1. General methodology and results. J Clean Prod 2005;13:213-9.

François D, Fantozzi C. Existing specific national regulations applied to material recycling. Deliverable No 4 of the Sustainable and Advanced Materials for Road InfraStructure (SAMARIS) GROWTH project of the European Commission (Nantes); 2004.

François D, Jullien A, Kerzreho JP, Chateau L. Full-scale experimentations on alternative materials in roads: Analysis of study practices. Waste Manage 2009;29:1076-83.

Goedkoop M. The Eco-indicator 95: description of the impact assessment methodology, NOH report 9514 A. Amersfoort, NL: PRé Consultants; 1996, July, 1995 Available online: http://www.pre.nl/eco-indicator95/eco-indicator95.htm.

Hoang T. Tronçons autoroutiers: une méthodologie de modélisation environnementale et économique pour différents scénarios de construction et d'entretien. Ph.D. from Laboratoire Central des Ponts et Chaussées and Ecole Centrale de Nantes; 2005, November, 3rd, 322 p. Available online: http://media.lcpc.fr/ext/ pdf/theses/rou/-tung_hoang.pdf.

Huijbregts MAJ, Thissen U, Guinée JB, Jager T, Kalf D, van de Meent D, et al. Priority assessment of toxic substances in life cycle assessment. Part I. Calculation of toxicity potentials for 181 substances with the nested multimedia fate exposure and effects model USES-LCA. Chemosphere 2000;41:541-73.

IPCC (Intergovernmental Panel on Climate Change). Fourth assessment report, $\mathrm{Cli}$ mate Change 2007 the physical science basis. Chapter 2. Changes in Atmospheric constituents and radiative forcing; 2007, 106 p., http://www.ipcc.ch/pdf/ assessment-report/ar4/wg1/ar4-wg1-chapter2.pdf.

IISI (International Iron and Steel Institute). World steel life cycle inventory. Methodology report 1999/2000 from Committee on environmental affairs, Brussels: 2002.

Jullien A, Monéron P, Ventura A, Legret M, Demare D, de la Roche C. Analyse de Cycle de Vie appliquée à un chantier d'entretien routier sur la RN 76-Evaluation technique et environnementale d'une couche de liaison d'enrobé bitumineux pour différents taux de recyclage. Ed. LCPC (Paris) coll. Etudes et Recherches des Laboratoires des Ponts et Chaussées; 2006.

Lafarge Cement. Environmental performances of cement works in the United King dom from 1999 to 2005; 2005, published on http://www.lafargecement.co.uk/ default.asp?skipCheck=true.

Lee K-M, Park P-J. Estimation of the environmental credit for the recycling of granulated blast furnace slag based on LCA. Res Cons Recycl 2005;44:139-51.

Lundström K. Influence des chaussées en béton et asphalte sur le milieu. In: 8th International Symposium on Concrete Road, 13-16, Lisbon, Portugal. Theme V: Safety and Environment; 1998. p. 195-202.

Martaud T, Jullien A, Deneele D, Proust C, Lédée V. In: Ressource en granulats: une démarche pour la prise en compte d'indicateurs de développement durable; 2007, 9 p.
Ministère de l'Equipement, du Logement et des Transports. Guide technique de réalisation des remblais et des couches de forme (Technical Guide for the Construction of Embankments and Capping Layers). Paris: Ed. MELT; 2000.

Monéron P, Ventura A, Jullien A, Paranhos R, Schemid M. Mesures d'émissions gazeuses sur le TSM17 du parc routier de Blois appliquées à la fabrication d'une grave bitume de classe 2. Report from LCPC TGCE/SDD/01-2006; 2006, $63 \mathrm{p}$.

Mroueh UM, Mäkela E, Wahlström M. By-products in earth construction. Assessment of acceptability. VTT chemical technology; 2000, $52 \mathrm{p}$.

Mroueh UM, Eskola P, Laine-Ylijoki. Life-cycle impacts of the use of industrial by-products in road and earth constructions. Waste Manage 2001;21: 271-7.

OFRIR (Observatoire Français du Recyclage dans les Infrastructures Routières); 2008 http://ofrir.lcpc.fr.

Park K, Hwang Y, Seo S, Seo H. Quantitative assessment of environmental impacts on life cycle of highways. J Constr Eng Manage 2003(January/February): 25-31.

Pereira A, Blanc I, Coste JF. La consommation énergétique globale des infrastructures autoroutières. Contribution à l'analyse de cycle de vie, vol. 210 (4137). Bull. Laboratoires Ponts Chaussées; 1997. pp. 95-104.

Pontarollo G, Smith T. A life-cycle analysis of the environmental impacts of asphalt and concrete road. In: IRF World Road Congress, Paris; 2001.

Rouwette RRJH, Schuurmans A. LCA concrete motoway pavement. Final report for critical review IN 01/18, Belgium; 2001.

Sayagh S. Approche multicritère de l'utilisation de matériaux alternatifs dans les chaussées, Ph.D. from Ecole Nationale des Ponts et Chaussées, Paris; 2007.

SETRA/LCPC (Service d'Etudes Techniques des Routes et Autoroutes, Laboratoire Central des Ponts et Chaussées). Réseau routier national. Catalogue des structures types de chaussées neuves. Guide technique. Paris: Ed. METL; 1998.

Stripple H. Life cycle inventory of asphalt pavements. Rapport IVL Swedish Environmental Research Institute Ltd. (Gothenburg); 2000.

Stripple H. Life cycle assessment of road. A pilot study for inventory analysis. Report IVL Swedish Environmental Research Institute Ltd (Gothenburg); 2001.

UNPG (Union Nationale des Producteurs de Granulats, Le marché des granulats). Leaflet, 2006. Paris: Ed. UNPG; 2005.

Vares S., Häkkinen T. Environmental burdens of concrete and concrete products Technical paper from the Technical Research centre of Finland, VTT Building Technology, Nordic Concrete Research 21; 1998:15 p. Available online: http://www.itn.is/ncr/publications/doc-21-10.pdf.

Ventura A, Jullien A, Sayagh S, Hoang T, Crozet Y. L'évaluation environnementale des infrastructures routières par la méthode des modules routiers. Rev Gén Routes Aérodromes 2008a;865:38-43.

Ventura A, Monéron P, Jullien A. Environmental impact assessment of a binding course of a pavement section, recycled at varying rates by the life cycle analysis methodology. J Road Mater Pav Des 2008b;9:319-38. 